ARTIGOS

\title{
FORMAÇÃO CONTINUADA DE PROFESSORES: REFLEXÕES SOBRE O DESENVOLVIMENTO DO RACIOCÍNIO MULTIPLICATIVO NO CICLO DE ALFABETIZAÇÃO
}

Eliane Kiss de SOUZA

Secretaria de Educação - SEDUC

São Leopoldo, RS - Brasil

elianekiss@gmail.com

https://orcid.org/0000-0001-5703-9254

Beatriz Vargas DORNELES Universidade Federal do Rio Grande do Sul - UFRGS

Porto Alegre, RS - Brasil

bvdornel@terra.com.br

https://orcid.org/0000-0002-0141-9140

Sérgio Roberto Kieling FRANCO

Universidade Federal do Rio Grande do Sul - UFRGS

Porto Alegre, RS - Brasil sergio.franco@ufrgs.br

https://orcid.org/0000-0002-1221-1310

RESUMO: Neste artigo analisa-se a eficácia da formação continuada de professores através dos resultados de grupos experimentais A, B e grupo controle, em relação ao desempenho dos alunos do $3^{\circ}$ ano do ensino fundamental na resolução de situações-problema com distribuição/partição e multiplicação. Para tal, foi desenvolvido para os grupos experimentais A e B um processo de formação sobre o desenvolvimento do raciocínio multiplicativo a partir dos conhecimentos prévios dos alunos, coletados na aplicação de um pré-teste. Verificou-se o efeito da formação continuada ao comparar o emprego de estratégias e o percentual de acerto dos alunos no pré-teste e nos pós-teste 1 e 2, com análise qualitativa e quantitativa. Os resultados evidenciaram que o processo de formação continuada junto ao grupo experimental B, com participação espontânea dos professores, contribuiu na construção coletiva dos saberes docentes e no desempenho dos alunos.

PALAVRAS-CHAVE: Formação Continuada de Professores. Raciocínio Multiplicativo. Desenvolvimento dos Alunos. 


\title{
CONTINUED EDUCATION PROGRAMME: REFLECTIONS ON THE DEVELOPMENT OF MULTIPLICATIVE REASONING IN THE LITERACY CYCLE
}

\begin{abstract}
In this article we describe the efficacy of a continued education program analyzing the results of experimental groups A, B and control group, in relation to the performance of the elementary school 3rd year students in there solution of problem situation swith distribution/partition and multiplication. For this, a training process with reflexive practice on the development of multiplicative reasoning was developed for the experimental groups $A$ and $B$, based on the students previous knowledge, collected in a pre-test application. We verified the effect of continued education comparing the use of strategies and the percentage of students' achievement in pre-testand post-test 1 and 2, with qualitative and quantitative analysis, using a statistical analysis software for the latter one. The results showed that the continued education process with the experimental group B, with spontane oust eacher participation, contributed to the collective construction of the teaching knowledge and, in a significant way, to the students' performance.
\end{abstract}

KEYWORDS: Continued Education Programme; Multiplicative Reasoning; Student Development

\section{FORMACIÓN CONTINUA DEL PROFESORADO: REFLEXIONES SOBRE EL DESARROLLO DEL RAZONAMIENTO MULTIPLICATORIO EN EL CICLO DE ALFABETIZACIÓN}

RESUMEN: Este artículo analiza la efectividad de la formación continua del profesorado por medio de los resultados de dos grupos experimentales $\mathrm{A}$, B y grupo control en relación al desempeño de los estudiantes de $3^{\circ}$ año de primaria en la resolución de situaciones problemáticas con distribución/partición y multiplicación. Para ello, se desarrolló un proceso de formación para los grupos experimentales A y B sobre el desarrollo del razonamiento multiplicativo basado en los conocimientos previos de los estudiantes, recogidos en la aplicación de un pre-test. El efecto de la educación continua se verificó al comparar el uso de estrategias y el porcentaje de aciertos de los estudiantes en el pre-test y en el post-test 1 y 2, con análisis cualitativo y cuantitativo. Los resultados mostraron que el proceso de formación continua con el grupo experimental B, con participación espontánea de los docentes, contribuyó a la construcción colectiva del conocimiento docente y el desempeño del estudiante.

PALABRAS CLAVE: Formación continua del profesorado. Razonamiento multiplicativo. Desarrollo estudiantil 


\section{Introdução}

Na Educação Básica, a escola tem como função promover estudos sobre os conhecimentos científicos construídos e acumulados pela humanidade, além da socialização dos indivíduos no processo educacional. $\mathrm{O}$ professor tem como tarefa docente planejar, conduzir as ações e avaliar o processo de ensino-aprendizagem dos alunos (LIBÂNEO, 2013). Esse processo envolve conhecimentos selecionados, organizados e alinhados em eixos estruturantes para cada componente curricular, por área do conhecimento, conforme currículo oficial. Por isso, o professor precisa estar em constante formação para desempenhar suas atribuições docentes com êxito. (BRASIL, 2010b). Essa eficiência e qualidade, pressupõem com atividades lúdicas, contextualizadas e trabalho interdisciplinar (MUNIZ, 2010; MENDES GOMES e SILVA, 2015; ALBUQUEROUE, LEAL e PESSOA, 2015).

De acordo com Ferreira (2012), dois segmentos estão relacionados à formação continuada de professores: o governo, responsável por criar estratégias para nortear as ações políticas para o desenvolvimento e melhoria da educação, e a academia, à qual "cabe realizar pesquisas científicas que sinalizem, por meio de novas teorias, questões que possam promover mudanças na prática docente e, consequentemente, no aprendizado do aluno" (FERREIRA, 2012, p. 10). Pode-se ilustrar tal intencionalidade com a oferta do Programa Pacto pela Alfabetização na Idade Certa (PNAIC), realizado de 2013 a 2017.

Nos últimos anos, na área da Alfabetização Matemática, sob perspectiva do letramento, as pesquisas vêm adquirindo mais espaço e força diante das necessidades de mudanças institucionais, acadêmicas e pedagógicas, visando atender ao perfil docente para atuar no Ciclo de Alfabetização da Educação Básica.

É a partir desses pressupostos que se analisa uma proposta de formação continuada com professores do $3^{\circ}$ ano do Ciclo de Alfabetização1, pautada pela prática reflexiva, pela socialização e pela cooperação. Foram analisadas as estratégias utilizadas pelos alunos na resolução de situações-problema envolvendo o raciocínio multiplicativo e as práticas propostas pelos professores em sala de aula, junto à reflexão teórica e intervenções pedagógicas. Para essa análise foram considerados dados coletados em testes aplicados aos alunos2.

Nesse artigo, foram revistas as concepções sobre a formação de professores e as relações numéricas estabelecidas em situações de raciocínio multiplicativo, com base em esquemas de ação por correspondência um-para-muitos e distribuição/partição, bem como os esquemas de divisão/quota e divisão ao meio, abordados por Nunes e Bryant (1997), Park e Nunes (2001), Nunes e colaboradores (2009) e estudos de Vergnaud (1983; 1993). Em seguida, descreve-se o processo formativo de professores3 e a análise e discussão dos dados coletados, que mostrou a evolução das estratégias utilizadas pelos alunos na resolução das situações-problema através do seu desempenho. Os resultados foram analisados com base no tripé "prática/teoria/ prática", mobilizando os saberes docentes e efetivação do conhecimento por parte dos alunos.

\section{Formação Continuada de Professores}

Para iniciar a reflexão sobre a formação continuada de professores, é importante revisitar as concepções que orientam a prática docente. A concepção de uma formação única para atuar em atividades docentes aos poucos está sendo substituída pela ideia de uma formação contínua, ao longo da vida profissional do professor. Nas últimas décadas, reconhece-se que a formação em magistério e/ou uma licenciatura não prepara para a atuação docente durante seu tempo de serviço, o que caracteriza os movimentos de políticas de 
formação (FERREIRA, 2012). A partir disso, a formação continuada tem como finalidade atender à demanda sócio-política, econômica e cultural de uma sociedade em constante mudança.

O reconhecimento da importância da formação continuada deu-se a partir de pesquisas sobre a formação de professores, tais como as de Tardiff (2000 e 2002). Em relação aos conceitos matemáticos iniciais, temática desse texto, Nacarato, Mengali e Passos (2009) reconheceram que, mesmo em condições adversas de trabalho e com lacunas em sua formação inicial, os professores se revelam comprometidos com a aprendizagem dos alunos e aceitam novas abordagens. O que lhes falta, de acordo com os autores, é oportunidade de vivenciar processos formativos durante o serviço.

Com base nas pesquisas acadêmicas, o professor e o programa de formação docente4 é um dos elementos constitutivos para a operacionalização das diretrizes curriculares nacionais gerais da Educação Básica no Brasil (BRASIL, 2010b). Diante disso, a preparação dos professores passa a ser considerado um dever dos programas de formação inicial e continuada, cujas Diretrizes Curriculares para a Educação Básica estabelecem:

a) além de um conjunto de habilidades cognitivas, saber pesquisar, orientar, avaliar e elaborar propostas, isto é, interpretar e reconstruir o conhecimento coletivamente;

b) trabalhar cooperativamente em equipe;

c) compreender, interpretar e aplicar a linguagem e os instrumentos produzidos ao longo da evolução tecnológica, econômica e organizativa;

d) desenvolver competências para integração com a comunidade e para relacionamento com as famílias. (BRASIL, 2010b).

A formação continuada é instituída na legislação brasileira para os profissionais da Educação Básica, de modo a complementar as lacunas deixadas pela formação inicial. Isso é proposto, sobretudo, com sentido de possibilitar a construção de saberes necessários aos professores, para que, em suas práticas, seja concretizada a reforma curricular estabelecida nas últimas duas décadas (BRASIL, 2010b). Formação pautada pela autonomia docente, socialização e cooperação no trabalho em equipe, ação em prática/teórica/prática, construção da identidade do professor e empenho para profissionalizar-se (FERREIRA, 2012).De modo que, no processo formativo, ocorra a mobilização de diferentes saberes que permitam repensar as práticas escolares em prol do conhecimento efetivo dos alunos. Nesse contexto, o processo continuado é considerado um espaço para refletir sobre atitudes; estratégias metodológicas e modos de organização do trabalho pedagógico; avaliação externa e interna; e, ainda, o estabelecimento de relações com as ações práticas, ou seja, a (re)construção de concepções sobre o processo de ensino e aprendizagem.

Com relação à complexidade da formação inicial e continuada, Ferreira e Leal (2010) pontuam que ocorre um descompasso entre as duas modalidades. Tem-se enfatizado mais a teoria na formação inicial e a prática na continuada, sendo a inicial voltada para estudantes e a continuada para profissionais. Os autores destacam que é necessário considerar um fator que interfere na formação continuada: o de nem sempre a participação partir de um interesse individual como ocorre na formação inicial. Muitas vezes, na formação continuada, o profissional participa "obrigado", sob a intenção da gestão escolar e/ou da Secretaria de Educação em meIhorar o desempenho do professor e a aprendizagem dos alunos. Essa participação "obrigada" gera conflitos com as mantenedoras das instituições escolares. Por isso, Imbernón (2010) afirma que se deve primar pelo equilíbrio entre a teoria e a prática, seja na formação inicial ou continuada.

Em relação à formação continuada, Canário (2006) adverte que essa modalidade não pode se tornar uma corrida às certificações ou, ainda, passar a ser considerada como uma atividade extra à carga horária, 
sobrecarregando as atividades docentes. O interesse pela certificação pode ter como consequência a participação por "obrigação" e de "modo penoso". (SOUZA, 2014).

Por isso, Canário (2006), Imbernón (2010), Ferreira e Leal (2010), Freire (2016), propõem um processo formativo continuado centrado no contexto de trabalho do professor, com reflexões sobre sua prática. Entretanto, deve contemplar os seguintes princípios: a prática da reflexividade, com análise das ações práticas, confrontando-as com a teoria, para então repensá-las; a mobilização dos saberes docentes, reconhecendo que estão em constante construção; a constituição da identidade profissional, revivendo memórias e repensando sua história; a socialização, com atividades em grupo; o engajamento, pelo desejo de aprender e descobrir coisas novas, valorizando seus conhecimentos prévios; e a colaboração, com sua participação ativa em relação à sua profissionalização. (FERREIRA, 2012).

Para Imbernón (2010), esse processo deve proporcionar: construção de aprendizagem coletiva, a partir da troca de experiências e interação entre pares; reflexão crítica sobre a prática; momentos para compartilhar boas práticas, sob valorização de diferentes experiências; experiências com estratégias formativas promovendo discussão de exemplos; e leituras para a compreensão das temáticas em reflexão.

Sob a concepção da formação continuada de professores como condição necessária para compreender que não se ensina para avaliar, mas que se avaliam os conhecimentos prévios para ensinar, de modo a propiciar avanços conceituais, será realizada a reflexão do desenvolvimento do raciocínio multiplicativo.

\section{Desenvolvimento do raciocínio multiplicativo}

No Ciclo de Alfabetização, segundo a perspectiva de alfabetizar letrando, o trabalho de desenvolvimento do raciocínio multiplicativo deve contemplar situações-problema não como forma de treinar o uso de algoritmos, mas com o uso das operações em diferentes contextos e práticas sociais para haver um sentido para os cálculos e operações efetuadas. (BRASIL, 2014). Para que a Alfabetização Matemática se efetive, é necessário conhecer as especificidades, a trajetória da forma de pensar e a lógica do processo de aprendizagem. (NUNES; BRYANT, 1997).

Para tal, o professor deve saber que o raciocínio multiplicativo envolve situações de multiplicação e divisão, com relações fixas entre variáveis, em esquemas de ação de correspondência um para muitos, distribuição/ partição, divisão/quota e divisão/cortes sucessivos. As situações de distribuição/partição, de divisão/quota e de divisão/cortes sucessivos se constituem em relações parte-todo, com três elementos (o todo, as partes e o tamanho das partes ou da quota) em uma distribuição equitativa. (SOUZA, 2014).

Nesse raciocínio, há uma série de sentidos com números novos a serem aprendidos, como proporções, fatores escalares e fatores funcionais (NUNES; BRYANT, 1997). As estruturas desse raciocínio, de acordo com Vergnaud (1983; 1993), abrangem tanto regras operatórias referentes à divisão e à multiplicação, quanto à combinação de ambas, em associação às situações de uso e aos suportes de representação, desenvolvidas pela criança de forma gradual por se tratar de situações complexas.

A seguir, um exemplo de situação, multiplicação/correspondência um-para-muitos, cuja base conceitual é a proporção:

Em uma moto há duas rodas. Quantas rodas há em quatro motos? 
Nesse exemplo, tem-se o conjunto "moto" e "rodas". Nos dois conjuntos há uma relação fixa, duas rodas por moto. "Cada vez que se acrescenta uma moto ao conjunto 'motos' também se acrescentam duas rodas ao conjunto 'rodas'. [...] Assim, na situação de relações entre os conjuntos ocorre a replicação mediante a adição da unidade correspondente". (SOUZA, 2014, p.35). A proporção entre os conjuntos "moto" e "rodas" permanece constante (1:2). Assim, na correspondência um para muitos (uma moto = duas rodas; duas motos = quatro rodas; três motos = seis rodas; quatro motos = oito rodas), tem-se "um fator escalar que não se relaciona ao conjunto motos e rodas, nem ao número de objetos nesses dois conjuntos, mas ao número de replicações". (SOUZA, 2014, p.35).

Exemplo de situação-problema com distribuição/partição:

Ana tem 15 balas e quer dividir entre três crianças. Quantas balas cada uma vai receber?

Nesse exemplo os três elementos são: as 15 balas (o todo), três crianças para partilhá-las (três partes) e as cinco balas por crianças (o tamanho da parte ou quota).

O que será determinado serão a quantidade de balas por receptor, no caso, as balas serão distribuídas entre as crianças. Há uma relação constante de balas por crianças. Nesse exemplo, serão distribuídas quantidades iguais entre cada receptor, com correspondência um-a-um, até esgotar os elementos (balas), embora haja situações em que a distribuição encerra quando se tem sobra de elementos por não ser possível distribuir de forma equitativa entre os receptores. (NUNES; BRYANT, 1997).

Exemplo de situação-problema com divisão/quota, envolvendo formação de grupos:

Ana dividiu 15 balas em pacotes, sendo que ela colocou cinco balas em cada pacote. Quantos pacotes foram utilizados?

Nesse exemplo, as crianças usam o esquema de ação um para muitos na resolução, formando grupos de cinco balas até esgotar o número de elementos, à exceção de situações em que a organização dos grupos se encerra quando há sobra de elementos por não ser possível formar mais um grupo com a quantidade de elementos estabelecidos. (NUNES e BRYANT, 1997; GUERIOS, AGRANIONIH e ZIMER, 2014).

A seguir, exemplo de situação por divisão/cortes sucessivos:

Maria tem três laranjas para dividir entre duas crianças. Quanto receberá cada criança?

Na divisão ao meio, ocorre uma relação inversa entre número de receptores e o tamanho da quota por uma série de divisões ou cortes sucessivos, partição que resulta em frações. No exemplo, cada criança receberá uma laranja e meia $(1,5)$, o tamanho da parte ou quota pode ser representada por uma fração imprópria (3/2), pois cada criança receberá três metades se todas as laranjas forem cortadas ao meio. Ainda, o tamanho da parte ou quota pode ser representada por uma fração mista (1 1/2). (NUNES; BRYANT, 1997). Dessa forma, as frações, além de representarem um sentido novo de número, são também um novo tipo de número. (SOUZA, 2014).

Em relação às situações-problema apresentadas, Nunes e colaboradores (2009) e Guerios, Agranionih e Zimer (2014) afirmam que as crianças são capazes de criar estratégias para resolver problemas com raciocínio 
multiplicativo muito antes do ensino sistematizado na escola. Elas criam estratégias iniciais/simples relacionadas a um tipo de experiência para a resolução de situações-problema, as quais vão evoluindo até chegar às mais econômicas, com representações instituídas por sistemas convencionais da cultura em que estão inseridas, como o uso de algoritmos a partir do ensino na escola. (SOUZA, 2014; LOPES, 2014).

As estratégias iniciais/simples contemplam: a contagem dos dedos ou material manipulativo, a contagem de desenhos com representação de riscos ou ilustrações da situação- problema e a distribuição um a um (com ações de ligar, enumerar e classificar os elementos). Já as econômicas: o uso de algoritmos com adição repetida, o uso de algoritmos com cálculo de multiplicação, o uso de algoritmos com cálculos de divisão. (SOUZA, 2014). As econômicas são assim denominadas por serem mais eficientes e rápidas, com economia de tempo na resolução de uma situação-problema, sendo assim consideradas mais avançadas e elaboradas.

Sabe-se que "diante de uma situação-problema, o aluno escolhe uma determinada estratégia, a qual envolve dois aspectos: a compreensão do problema e os procedimentos para resolvê-lo". (SOUZA, 2014, p.42). E, à medida que a criança cresce, ela conquista maior autonomia e desenvolve estratégias mais elaboradas, diminuindo erros.

Para Guérios e Ligeski (2013), os erros em situações-problema ocorrem por duas naturezas: dificuldade de compreensão de natureza matemática, causada por limitação na compreensão de conceitos, e/ou dificuldades linguísticas. Para cada uma dessas naturezas, de acordo com Guerios, Agranionih e Zimer (2014), há estratégias diferenciadas de intervenção pedagógica.

\section{Método}

Optou-se pela realização de um estudo correlacional de caráter quali-quantitativo, com um método misto, conforme proposto por Creswell (2007), cuja eficácia está na possibilidade dos resultados quantitativos e qualitativos complementarem-se. Isso, sem priorizar uma forma de análise dos dados, porque ambas são inseparáveis e interdependentes. (MINAYO, 2007). Na perspectiva qualitativa realizou-se a análise da eficácia do programa continuado de formação de professores quanto às evoluções nas estratégias utilizadas pelos alunos para a resolução das situações-problema, elencando os erros apresentados. No programa, pelos registros escritos no questionário, aplicado antes e após a formação, e na ficha de autoavaliação após cada encontro, juntamente com observações diretas de participação, considerando os argumentos, as expressões utilizadas e, ainda, as atitudes dos professores ao participarem das atividades propostas. Já na quantitativa, foi analisado o desempenho dos alunos do $3^{\circ}$ ano do Ensino Fundamental quanto à média de acertos nos grupos experimentais $A, B$ e o grupo controle quanto à avaliação das variações nos três blocos aplicados. (SOUZA, 2014).

Na pesquisa de campo, foram aplicadas duas situações-problema envolvendo raciocínio multiplicativo, em três momentos, sendo um antes da formação continuada de professores e dois após. A pesquisa foi realizada em redes de ensino público, localizadas na região metropolitana de Porto Alegre (RS). Sendo: a rede municipal de Novo Hamburgo (RS), com apoio da Secretaria Municipal de Educação, e a estadual no município de São Leopoldo (RS), pertencente à $2^{a}$ Coordenadoria Regional de Educação (CRE). Em ambas as redes, a amostra foi composta por 16 professores regentes do $3^{\circ}$ ano do Ciclo de Alfabetização e 248 alunos. Os professores e alunos foram divididos em dois grupos: experimental e controle. Os professores do grupo experimental foram subdivididos em grupo experimental A, com inscrição por convocação, e em grupo experimental B, com inscrição de livre escolha da formação continuada. Os professores do grupo controle não participaram do programa de formação. 
Para a análise quantitativa, o "efeito da formação continuada, no pós-teste 1 e no pós-teste 2, para os grupos experimentais A e B e também em relação ao grupo controle". (SOUZA, 2014, p.98), foi realizado uma análise para medidas repetidas, com adoção de nível de significância de $5 \%$, através do uso do teste de comparações múltiplas Bonferroni, quando necessário. Para a análise qualitativa, fez-se a análise de conteúdo e de discurso, com base nos processos de unitalizar5 e categorizar6, criando meta-textos analíticos/textos interpretativos (MORAES; GALIAZZI, 2007), utilizando a Análise Textual Discursiva.

\section{A formação continuada dos professores}

O programa de formação continuada para os professores do grupo experimental A e B foi realizado durante cinco meses com 10 encontros quinzenais de duas horas, totalizando 20 horas. Assim, com base nos princípios da formação continuada estabelecidos por Ferreira (2012) e Imbernón (2010), foi proposto: trabalhos em grupo, com reflexão sobre as estratégias empregadas pelas alunos e o raciocínio multiplicativo; revisitado memórias de como aprenderam na escola a resolução de situações-problema; e analisado a ação prática em sala de aula. A proposta teve como base as tendências pedagógicas atuais e os estudos dos autores citados nesse texto, a partir de leituras prévias de textos disponibilizados, juntamente com oficinas práticas. Ao final de cada encontro, os professores realizaram autoavaliações em fichas individuais, registrando seus saberes docentes e a constante construção deles. Na ficha questionário, registraram o motivo da participação na formação, envolvendo as concepções de suas próprias formações profissionais.

Todo o processo foi pautado pelos princípios: da prática reflexiva, da socialização, do engajamento, da colaboração e da identidade do professor. (FERREIRA, 2012; CANÁRIO,2006; IMBERNÓN,2010; FREIRE 2016), e pelos indicadores dos resultados do pré-teste. Denominou-se pré-teste a primeira aplicação das situações-problema, conforme o Quadro 2, antes da participação dos professores no programa. O pós-teste 1 e pós-teste 2 foram reaplicados respectivamente, logo após o término da formação continuada e depois de seis meses.

No teste, constituído por um bloco com uma situação-problema por página, duas situações contemplaram questões sobre raciocínio multiplicativo, um de distribuição/partição e outro com multiplicação/correspondência um para muitos, conforme o Quadro 1.

\section{Quadro 1: questões do pré-teste/pós-teste sobre raciocínio multiplicativo}

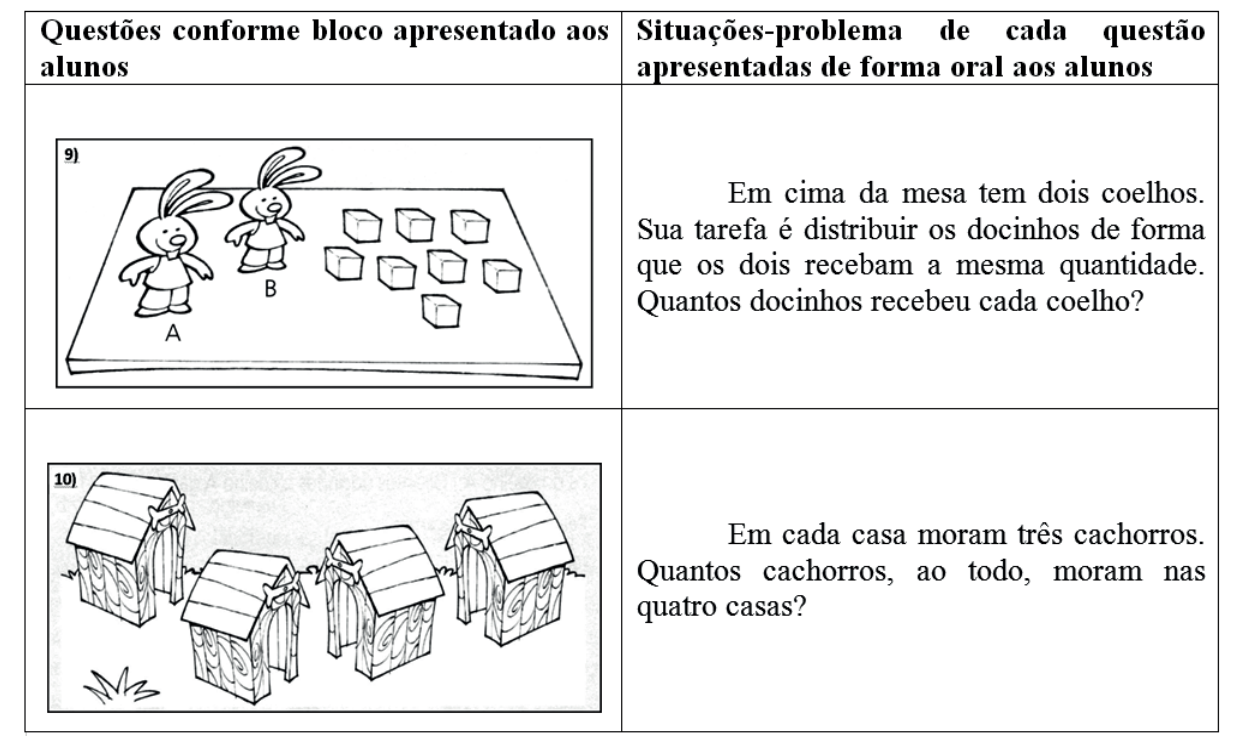

Fonte: adaptado de Nunes e colaboradores (2009) por Souza (2014) 
Análises qualitativas e quantitativas: das estratégias utilizadas na resolução das situações-problema e do desempenho dos alunos.

Na perspectiva qualitativa, foi realizada a análise da evolução das estratégias utilizadas pelos alunos em relação ao raciocínio multiplicativo segundo os registros feitos nas páginas do bloco de teste e pelas observações diretas durante a aplicação.

Com base na análise das estratégias dos alunos no pré-teste, em ambos os grupos experimental e controle, seguem extratos apresentados nas figuras e a classificação realizada, os quais influenciaram o processo de formação continuada dos professores.

Na questão (9) de distribuição/partição, com a utilização da correspondência um-a-um, em todas as 16 turmas foram encontradas as mesmas estratégias, as quais foram classificadas da seguinte maneira: E1: ligar os elementos (Figura 1a); E2: enumerar os elementos com letras A e B (Figura 1b), com os números 1 e 2, e com números de 1 a 4; E3:desenho termo-a-termo (Figura 1d); E4:agrupamento (Figura 1c); E5:cortes sucessivos com metades (Figura 1e); e E6: cálculo mental." (SOUZA, 2014). Em termos percentuais, apresenta-se cerca de: $10 \%$ para a E1; $10 \%$, para a E2; $12 \%$, para a E3; $18 \%$, para a E4; $1 \%$, para a E5; e 30\%, para a E6.

Com base nos registros pictóricos da Figura 1, evidencia-se que, antes da sistematização do ensino da multiplicação e divisão na escola, as crianças fazem a distribuição com a utilização de esquema de ação um-a-um de diversas formas, conforme a classificação apresentada.

\section{Figura 1 - Estratégias Utilizadas para a Questão sobre Divisão}

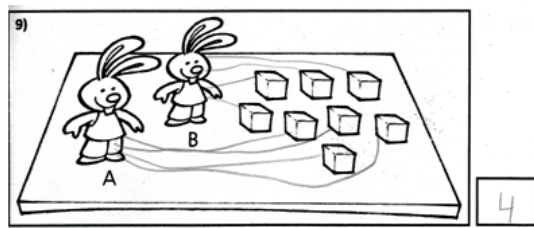

(a)

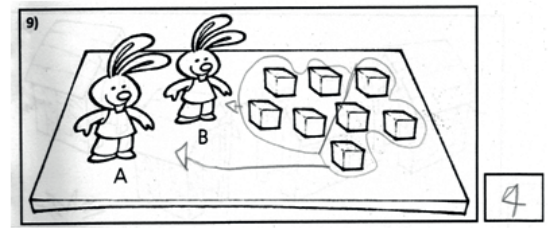

(c)

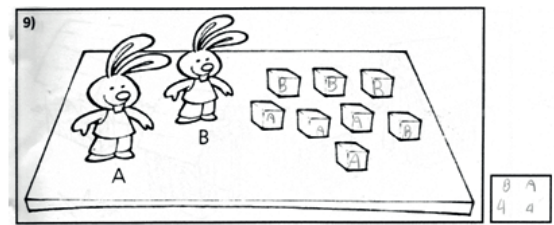

(b)

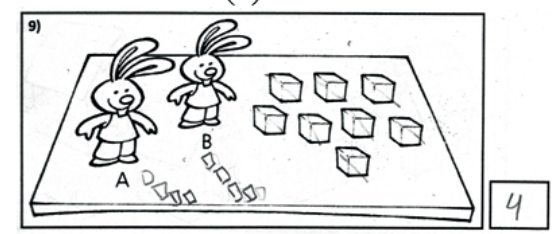

(d)

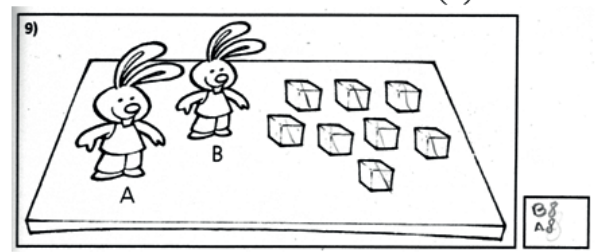

(e)

Fonte: Pré-teste (SOUZA, 2014).

Nunes e Bryant (1997) e Guerios, Agranionih e Zimer (2014) ajudam a compreender o emprego das estratégias inicias/simples dos extratos da Figura 1, comprovando as afirmações dos autores de que as crianças criam estratégias a partir de suas experiências no cotidiano, resolvendo as situações-problemas sem o uso 
de algoritmo, com predominância da utilização do esquema um-a-um, antes da escolarização. Embora encontrado registro da divisão com cortes sucessivos, os alunos distribuíram as metades de modo que cada receptor recebeu 8, como se observa na Figura 1e. Como uso de cálculo mental, considerou-se as questões em que não havia nenhum registro pictórico no bloco.

Ainda vale destacar que, no registro "para A '4'e para B '4'" apresentado na Figura 1b, verificou-se compreensão parcial dos alunos quanto às relações entre o todo, as partes e o tamanho das partes. (SOUZA, 2014).

Na questão 10 de multiplicação com a utilização de esquema um-para-muitos, classificou-se as estratégias iniciais/simples utilizadas pelos alunos em: contagem nos dedos E1; e representação de desenhos, com palitinhos ou cachorros, E2. Com base na observação direta na aplicação da questão, estima-se que em torno de $50 \%$ dos alunos utilizaram a contagem nos dedos E1, independente da resposta estar correta. Constatou-se, dentre os que contavam usando os dedos, a contagem dos cachorros imaginados nas casas, com o balançar do dedo em cada casa, mas não foi possível tabular o percentual. Conforme ilustra a Figura 2, na E2 verificou-se que os alunos representaram a adição da unidade correspondente, a replicação da variável três (cachorro), com desenhos ou palitinhos embaixo das casas ou espalhados no bloco.

\section{Figura 2 - Estratégia Utilizada para a Questão 10 sobre Multiplicação}

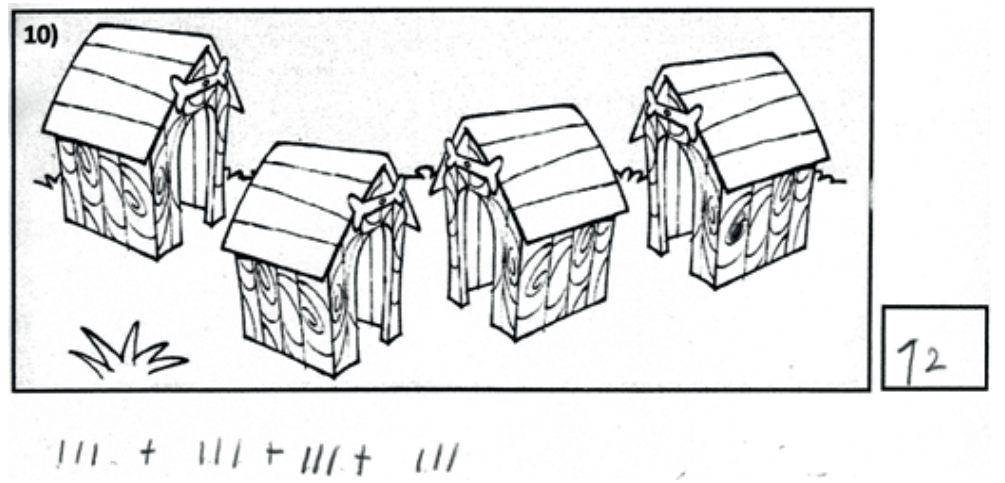

Fonte: Pré-teste (SOUZA, 2014).

Além das estratégias utilizadas no pré-teste, constatou-se nos pós-testes 1 e 2, aplicados após o processo formativo dos professores, que para a questão de distribuição/partição, os alunos utilizaram mais uma estratégia: a E5 - com o uso do cálculo escrito. Para a questão de multiplicação, mais três: a E3 - o uso da contagem com representação de algarismos; E4 - o cálculo escrito com adição; e E5 - o cálculo escrito com multiplicação. Verificou-se aumento no percentual pela opção do cálculo mental. Observa-se que, na Figura 3a, o aluno usou além das estratégias iniciais/simples E1, usou uma estratégia econômica, a E5, o cálculo escrito com a distribuição nos conjuntos.

Constatou-se, conforme (Figura 3b), na E3 uma nova forma de distribuição, com agrupamentos de dois em dois elementos Porém, com a estratégia usada, o aluno não conseguiu encontrar a solução ao problema que solicitava o tamanho das partes e não a quota (quantidade de partes), pois a situação-problema não era por divisão/quota, envolvendo formação de grupos. Assim, para responder quantos docinhos recebeu cada coelho, o aluno optou pela distribuição um-a-um dos docinhos, com risquinhos abaixo das letras $\mathrm{A}$ e B. Como hipótese para o uso da estratégia com agrupamento com dois elementos tem-se: 1) o ensino da tabuada, apresentando a multiplicação e a divisão como operações inversas; e 2) o ensino de procedimentos mecânicos ensinados para cálculos de divisão. 
Figura 3 - Estratégia utilizada para a questão sobre divisão

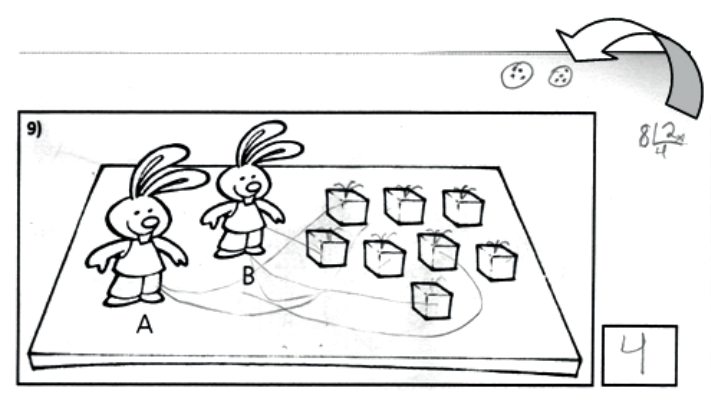

(a)

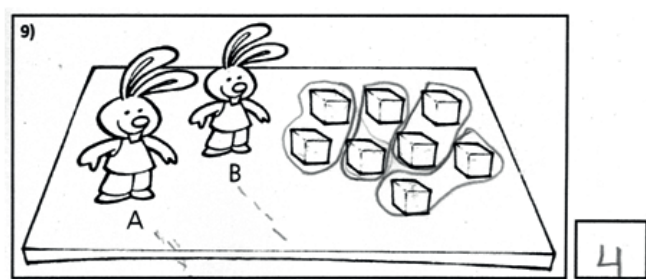

(b)

Fonte: Pós-teste 1 (SOUZA, 2014)

Os registros evidenciam que, após o estudo da multiplicação e divisão na escola, os alunos passam a usar representações ensinadas, com algoritmos. O desenvolvimento do raciocínio multiplicativo requer, de acordo com Nunes e Bryant (1997) e Guerios, Agranionih e Zimer (2014), a compreensão dos conceitos e a coordenação de diferentes sistemas de representação. Isso significa que, no processo de alfabetizar letrando, utiliza-se cálculos numéricos, pois à medida em que se amplia o campo numérico e as dificuldades das situações-problema, os cálculos vão tornando-se necessários. Por essa razão, os autores consideram fundamental que os alunos tenham interação com diferentes formas de registro.

Embora em número reduzido, os alunos continuaram a dividir os doces ao meio nos pós-testes, com distribuição das metades, em esquema um-a-um, utilizando duas formas de registro: oito metades para cada coelho (Figura 4a) e, somando as metades, registraram 16 (Figura 4b), visto que eram dois coelhos e havia apenas um retângulo para resposta. Cabe destacar que um aluno, conforme a Figura 4b, tentou fazer o cálculo escrito.

Figura 4 - Estratégia utilizada para a questão 9 sobre divisão

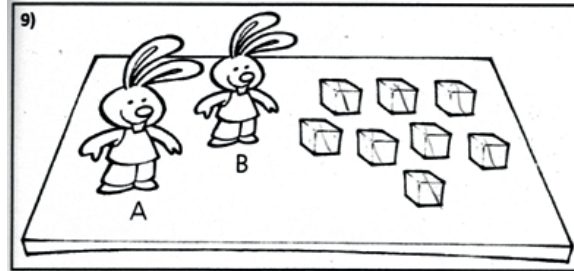

(a)

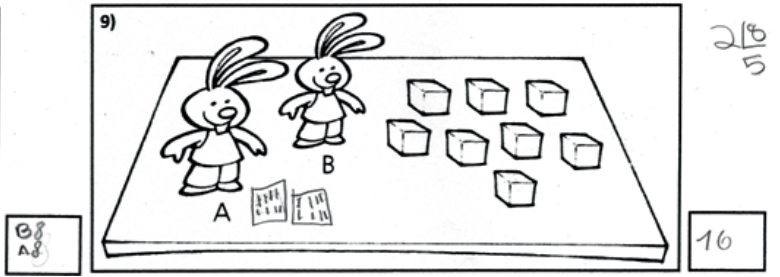

(b)

Fonte: Pós-teste 1 (SOUZA, 2014).

Esses achados demonstram a necessidade da mediação do professor, de acordo com Guerios, Agranionih e Zimer (2014), com intervenções pedagógicas específicas e individuais, para ajudar a criança a evoluir em concepções conceituais, emprego de estratégias, forma de registro dos resultados encontrados e, ainda, o uso de algoritmos.

Constatou-se na E3, nos pós-testes, que alunos dos grupos experimentais A e B passaram a substituir os desenhos (Figura 5a), em cada casa, pelos algarismos 3, 6, 9 e 12 ou, somente, pelo algarismo 3 (Figura 5b). Ainda, a opção pela E4 e E5, conforme a Figura5c e Figura5d, apareceu somente nos grupos experimentais $A$ e $B$. 
Figura 5 - Estratégias utilizadas para a questão 10 sobre multiplicação

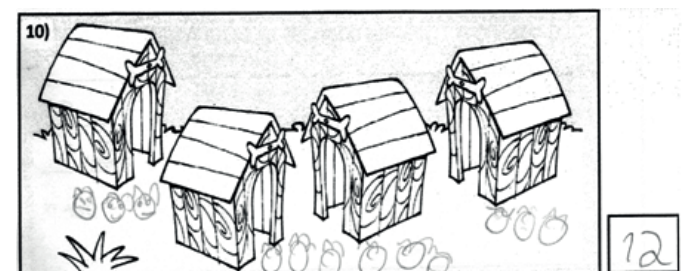

(a)

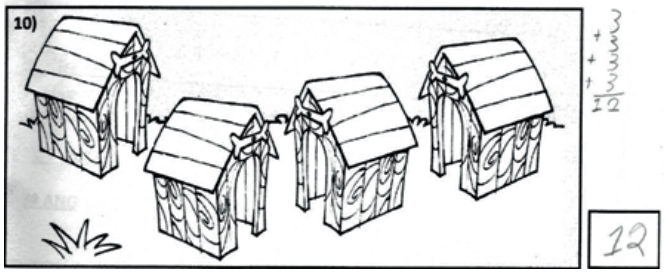

(c)

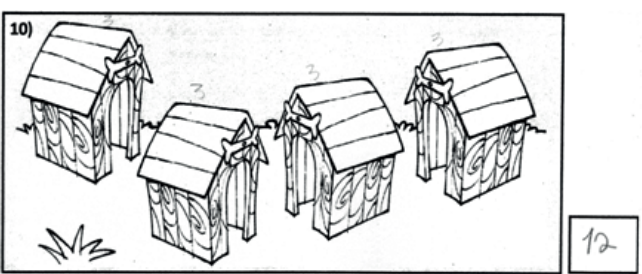

(b)

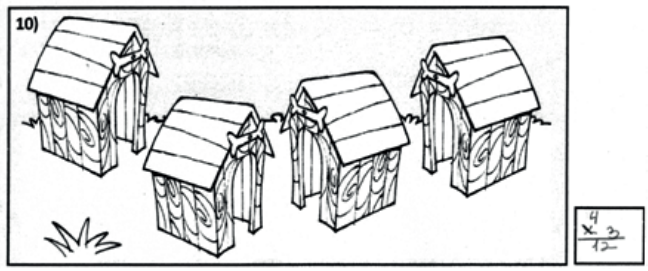

(d)

Fonte: Pós-teste 1 (SOUZA, 2014).

$\mathrm{Na}$ E4, o uso do algarismo 3 levou alunos dos grupos experimentais A e B a cometerem erros, pois eles se confundiram quanto ao número de replicações, com uma parcela a mais ou a menos no cálculo, $(3+3+3)$ ou $(3+3+3+3+3)$. Logo, nem todos que usaram a E4 acertaram a questão. Mesmo com o uso de estratégias mais econômicas nos pós-testes 1 e 2, constatou-se casos de troca de algarismos na representação do numeral 12. Embora o aluno soubesse que o resultado da questão era 12, pois escreveu " 3 " no telhado de cada casa (Figura 6), ainda assim trocou a ordem dos algarismos, registrando " 21 ".

Figura 6 - Estratégia utilizada para a questão 10 sobre multiplicação

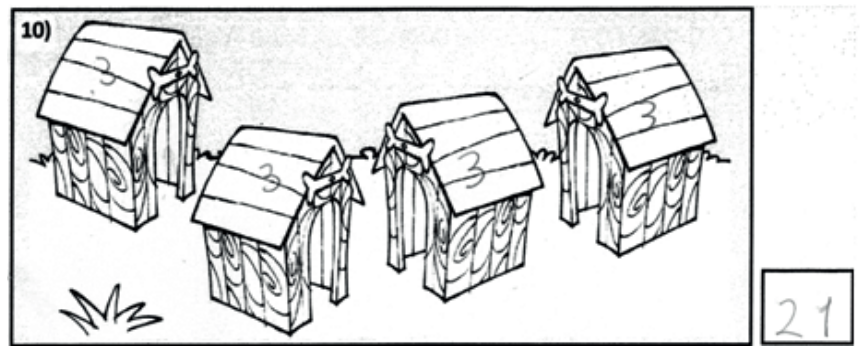

Fonte: Pós-teste 2 (SOUZA, 2014).

Com base nos achados, pode-se considerar que o emprego de estratégias mais econômicas, com o uso de algoritmos, não garante respostas corretas, conforme Lauter e Spinillo (2002) e Vergnaud (1983; 1993), essas dependem de compreensão conceitual mostrando que os erros em situações-problema podem ocorrer por compreensão de natureza matemática e por limites na compreensão de conceitos. (GUÉRIOS E LIGESKI, 2013).

Por fim, apresenta-se um quadro com percentual de escolhas de estratégias, conforme Quadro 2, para ilustrar a evolução das estratégias utilizadas pelos alunos em relação ao pré-teste. 


\section{Quadro 2: percentual das Estratégias Utilizadas na Solução das Questões}

\begin{tabular}{|c|c|c|c|c|c|c|c|c|c|c|c|c|}
\hline \multirow{2}{*}{ 串 } & \multirow{2}{*}{ 旁 } & \multirow{2}{*}{ 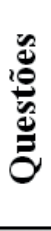 } & \multirow{2}{*}{ } & \multicolumn{3}{|c|}{$\begin{array}{c}\text { Grupo } \\
\text { experimental } A \\
(93 \text { alunos })\end{array}$} & \multicolumn{3}{|c|}{$\begin{array}{c}\text { Grupo } \\
\text { experimental B } \\
(121 \text { alunos })\end{array}$} & \multicolumn{3}{|c|}{$\begin{array}{l}\text { Grupo controle } \\
(34 \text { alunos })\end{array}$} \\
\hline & & & & $\begin{array}{l}\text { Pré- } \\
\text { teste }\end{array}$ & $\begin{array}{c}\text { Pós- } \\
\text { teste } 1\end{array}$ & $\begin{array}{c}\text { Pós- } \\
\text { teste } 2\end{array}$ & $\begin{array}{l}\text { Pré- } \\
\text { teste }\end{array}$ & $\begin{array}{c}\text { Pós- } \\
\text { teste } 1\end{array}$ & $\begin{array}{c}\text { Pós- } \\
\text { teste } 2 \\
\end{array}$ & $\begin{array}{l}\text { Pré- } \\
\text { teste }\end{array}$ & $\begin{array}{c}\text { Pós- } \\
\text { teste } 1\end{array}$ & $\begin{array}{c}\text { Pós- } \\
\text { teste 2 }\end{array}$ \\
\hline \multirow{11}{*}{ 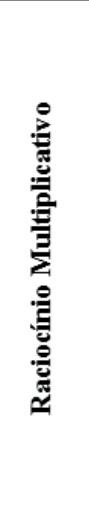 } & \multirow{11}{*}{5} & \multirow{7}{*}{9} & E1 & 11.83 & 3.23 & 2.15 & 6.61 & 6.61 & 4.96 & 26.47 & 26.47 & 26.47 \\
\hline & & & E2 & 11.83 & 10.75 & 6.45 & 11.57 & 5.79 & 7.44 & 11.76 & 8.82 & 5.88 \\
\hline & & & $\mathbf{E 3}$ & 12.90 & 8.60 & 6.45 & 14.05 & 3.31 & 2.48 & 14.71 & 8.82 & 5.88 \\
\hline & & & E4 & 16.13 & 17.20 & 10.75 & 28.10 & 17.36 & 10.74 & 11.76 & 8.82 & 8.82 \\
\hline & & & E5 & 0.00 & 1.08 & 1.08 & 0.00 & 9.92 & 11.57 & 0.00 & 0.00 & 0.00 \\
\hline & & & E6 & 4.30 & 2.15 & 0.00 & 4.96 & 2.48 & 0.83 & 5.88 & 5.88 & 2.94 \\
\hline & & & E7 & 43.01 & 56.99 & 73.12 & 34.71 & 54.55 & 61.98 & 29.41 & 41.18 & 50.00 \\
\hline & & \multirow{4}{*}{10} & E1 & 81.72 & 88.17 & 91.40 & 68.60 & 65.29 & 85.12 & 88.24 & 88.24 & 97.06 \\
\hline & & & E2 & 18.28 & 6.45 & 4.30 & 31.40 & 8.26 & 5.79 & 11.76 & 11.76 & 2.94 \\
\hline & & & $\mathbf{E 3}$ & 0.00 & 2.15 & 2.15 & 0.00 & 5.79 & 1.65 & 0.00 & 0.00 & 0.00 \\
\hline & & & E4 & 0.00 & 2.15 & 2.15 & 0.00 & 11.57 & 4.13 & 0.00 & 0.00 & 0.00 \\
\hline
\end{tabular}

Fonte: Dados da pesquisa (SOUZA, 2014).

No grupo controle, o percentual de alunos que optaram pela E2 no pós-teste 1 não difere do pré-teste. Nesse grupo não foi encontrado registro utilizando estratégias com representação numérica nas questões 9 , de divisão/partição e 10, de multiplicação. Nesse sentido, têm-se evidências de que o processo formativo dos professores participantes da formação continuada influenciou na evolução das estratégias empregadas pelos alunos do grupo experimental $A$ e $B$, sendo mais expressivo no grupo experimental $B$, cujos professores participaram por livre escolha. Os resultados apresentados confirmam as afirmações de Canário (2006) e Ferreira e Leal (2010), sobre a participação processo formativo continuado por obrigação não contribuir na melhora do desempenho docente e, consequentemente, na aprendizagem do aluno.

Pelas estratégias empregadas nas situações-problema e percentual de acertos, têm-se evidências de que o processo formativo teve mais impacto no grupo experimental B. Portanto, inferimos que a formação continuada dos professores que desejam aprender e buscam aperfeiçoamento profissional tem influência positiva no desempenho de seus alunos. Os professores desse grupo mobilizaram seus saberes e consequentemente, sua prática, em função da reflexão realizada a partir dos conhecimentos prévios de seus alunos e das discussões que surgiram ao socializarem a forma como desenvolviam seus trabalhos

\section{Percentual de acertos}

Embora na escola não se ensine a sistematização da multiplicação e divisão no $1^{\circ}$ e no $2^{\circ}$ ano no Ciclo de Alfabetização, constatou-se, conforme Quadro 3, que 83,03\% dos alunos acertaram a nona questão de divisão por distribuição/partição, e 73,08\%, a décima, de multiplicação. Com isso, pode-se afirmar que, ao iniciar o $3^{\circ}$ ano, os alunos possuem conhecimentos prévios, com base na experiência do cotidiano, possibilitando a utilização de estratégias iniciais/simples para a resolução de situações-problema envolvendo o raciocínio multiplicativo, resultado que vai na mesma direção dos estudos de Nunes e Bryant (1997). 


\section{Quadro 3: médias em Percentual de Acertos}

\begin{tabular}{|c|c|c|}
\hline \multirow{3}{*}{ Grupos } & Blocos & Raciocínio Multiplicativo \\
\hline \multirow{4}{*}{$\begin{array}{c}\text { Experimental A } \\
\text { (93 alunos) }\end{array}$} & Pré-teste & 81,45 \\
\cline { 2 - 3 } & Pós-teste 1 & 84,66 \\
\cline { 2 - 3 } & Pós-teste 2 & 86,67 \\
\cline { 2 - 3 } & Diferença entre Pré-teste e Pós-teste 1 & $3,22 \mathrm{~ns}$ \\
\cline { 2 - 3 } & Diferença entre Pós-teste 1 e Pós-teste 2 & $2,01 \mathrm{~ns}$ \\
\hline \multirow{3}{*}{$\begin{array}{c}\text { Experimental B } \\
\text { (121 alumos) }\end{array}$} & Pré-teste & 80,67 \\
\cline { 2 - 3 } & Pós-teste 1 & 91,27 \\
\cline { 2 - 3 } & Pós-teste 2 & 92,12 \\
\cline { 2 - 3 } & Diferença entre Pré-teste e Pós-teste 1 & $10,60 *$ \\
\cline { 2 - 3 } & Diferença entre Pós-teste 1 e Pós-teste 2 & $0,85 \mathrm{~ns}$ \\
\hline \multirow{3}{*}{$\begin{array}{c}\text { Controle } \\
\text { (34 alunos) }\end{array}$} & Pré-teste & 69,82 \\
\cline { 2 - 3 } & Pós-teste 1 & 73,07 \\
\cline { 2 - 3 } & Pós-teste 2 & 85,00 \\
\cline { 2 - 3 } & Diferença entre Pré-teste e Pós-teste 1 & $3,25 \mathrm{~ns}$ \\
\cline { 2 - 3 } & Diferença entre Pós-teste 1 e Pós-teste 2 & $11,93 *$ \\
\hline
\end{tabular}

Fonte: dados da pesquisa (SOUZA, 2014)

Para o raciocínio multiplicativo, em situações-problema com distribuição/partição e multiplicação/correspondência um-a-muitos, houve diferença significativa entre o pré-teste e o pós-teste 1somente no grupo experimental B, com o desempenho, em média, melhor no pós-teste 1. Na comparação entre o pós-teste 1 e pós-teste 2, houve diferença significativa somente no grupo controle, com desempenho melhor, em média, no pós-teste 2,conforme Tabela 1.

Tabela 1: descrição do Número Médio de Acertos por Bloco nos Grupos

\begin{tabular}{llrrrrrr}
\hline \multicolumn{1}{c}{ Grupos } & Blocos & Média & Desvio Erro & IC (95\%) & \multicolumn{2}{c}{ Valor-p $^{\text {\& }}$} & Valor-p $^{\#}$ \\
\hline \multicolumn{2}{l}{ Raciocinio Multiplicativo } & & & & & & \\
\hline \multirow{2}{*}{ Experimental A } & Pré-teste & 8,14 & 0,41 & 7,34 & 8,95 & & \\
& Pós-teste 1 & 8,47 & 0,41 & 7,65 & 9,28 & 0,426 & 0,667 \\
& Pós-teste 2 & 8,67 & 0,21 & 8,25 & 9,08 & & \\
\hline \multirow{2}{*}{ Experimental B } & Pré-teste & 8,07 & 0,23 & 7,62 & 8,52 & & \\
& Pós-teste 1 & 9,13 & 0,11 & 8,90 & 9,35 & $<0,001$ & 0,628 \\
& Pós-teste 2 & 9,21 & 0,15 & 8,93 & 9,50 & & \\
\multirow{2}{*}{ Controle } & Pré-teste & 6,98 & 0,46 & 6,08 & 7,88 & & \\
& Pós-teste 1 & 7,31 & 1,16 & 5,03 & 9,58 & 0,643 & $<0,001$ \\
& Pós-teste 2 & 8,50 & 1,06 & 6,42 & 10,58 & & \\
\hline
\end{tabular}

Fonte: dados da pesquisa (SOUZA, 2014)

Pelo percentual de acertos, constata-se, através dos percentuais de erros apresentados pelos alunos dos grupos experimentais e de controle nos pós-testes 1 e 2, que o ensino das estratégias não foi suficiente para a compreensão de conceitos matemáticos. Embora utilizando estratégias econômicas, conforme Souza (2014), há um percentual de alunos que não conseguiu solucionar situações-problema de forma correta, mesmo quando utilizavam estratégias iniciais/simples. 
Para que ocorra desenvolvimento do raciocínio multiplicativo, os alunos precisam entender as regras embasadas na lógica do número e compreender o sistema de numeração convencional, usando-o para pensar de forma significativa e apropriada na resolução de situações-problema (NUNES; BRYANT, 1997), de modo que combinem três processos interdependentes: relacionando conceitos a situações diversas, aos significados aprendidos e representando-os através de simbolizações. (VERGNAU, 1983; 1993). Portanto, noções envolvendo raciocínio multiplicativo, de domínio cognitivo, ao serem sistematizadas no contexto escolar, devem contemplar as relações numéricas e o uso das operações em diferentes contextos e práticas sociais para que ocorra um sentido nos cálculos e operações efetuadas (BRASIL, 2014).

Dos $27 \%$ de alunos que não acertaram a questão 10, de multiplicação, verificou-se a relação do erro a dois aspectos: à contagem com um elemento a mais (13), ou ao número de replicações, resultando em uma a mais (15). Em casos isolados, constatou-se que houve troca na ordem dos algarismos ao registrarem o resultado da resolução da situação-problema, de modo que representaram "12" como "21." Conforme Guérios e Ligeski (2013) e Guérios, Agranionih e Zimer (2014) os erros em destaque ocorreram por natureza matemática7. Logo, os exemplos ilustram a limitação na compreensão de conceitos do raciocínio multiplicativo, da composição dos números e da contagem, conforme afirmam Lauter e Spinillo (2002), por não saberem usar representações diversas relacionadas ao conhecimento sobre número, quantidade e algoritmos.

\section{Considerações finais}

Os resultados sugerem que a eficácia de um processo formativo para professores, com posteriores intervenções focalizadas, está diretamente relacionada às razões pelas quais os levariam a participar dos programas de formação continuada. A partir dos resultados dos pós-testes, constatou-se que o processo formativo pautado pela prática reflexiva, socialização e cooperação, mostrou-se mais eficaz para os professores do grupo experimental B, pois um maior percentual de alunos apresentou melhor desempenho e evolução no emprego das estratégias, passando a usar cálculos numéricos na resolução de situações-problema. Esse resultado indica que um percentual significativo de alunos desse grupo passou a coordenar os esquemas em ação com o raciocínio lógico matemático, desenvolvidos na vida diária, por meio do sistema de numeração convencional estudado na escola para resolução das situações-problema envolvendo distribuição/partição e multiplicação.

Os resultados sugerem que, para a evolução das estratégias e do desempenho dos alunos em conceitos matemáticos envolvendo raciocínio multiplicativo, é necessária uma intervenção focalizada, a partir da análise dos conhecimentos prévios dos alunos, coletados em pré-testes, antes que o professor introduza e aprofunde conceitos nos estudos propostos. Nesse sentido, a formação continuada é uma oportunidade para os professores refletirem sobre sua prática, tendo como base um referencial teórico, de forma que haja um equilíbrio entre as duas abordagens, sem priorização de uma, tendo como base o tripé: análise da prática/ teoria/prática, mobilização dos saberes docentes e efetivação da aprendizagem dos alunos.

10 Ciclo de Alfabetização é constituído pelos três primeiros anos do Ensino Fundamental, conforme a Resolução CNE/CEB 7/2010. (BRASIL, 2010a)

2 Os dados foram coletados na pesquisa "Formação Continuada de Professores na Área da Matemática Inicial" (SOUZA, 2014). Tese (Doutorado) Universidade Federal do Rio Grande do Sul, Faculdade de Educação, Programa de Pós-Graduação em Educação, Porto Alegre, BR-RS, 2014.

3A ação formativa descrita foi aplicada a um grupo de professores regentes do $3^{\circ}$ ano do Ensino Fundamental da rede pública da região metropolitana de Porto Alegre - RS. (SOUZA, 2014). 
4De acordo com o Art. 42 da Resolução CNE/CEB N 07/2010 b foram estabelecidos quatro elementos constitutivos para a operacionalização destas Diretrizes: o projeto político-pedagógico e o regimento escolar, o sistema de avaliação, a gestão democrática e a organização da escola, o professor e o programa de formação docente.

5No processo de unitalização ocorre a interpretação das ideias elementares de sentido sobre o tema pesquisado, sob a leitura de vozes dos sujeitos, em que o pesquisador assume a interpretação. (MORAES; GALIAZZI, 2007).

6 No processo de categorização, o pesquisador produz argumentos, reunindo as unidades de significados semelhantes. (MORAES; GALIAZZI, 2007).

7 Os de natureza matemática são os decorrentes de limitações na compreensão de conceitos envolvidos impedindo o estabelecimento das relações necessárias para a solução do problema[...] Ausência ou equívoco de compreensão matemática: o aluno compreendeu o que leu mas não identificou o conceito matemático que o resolve. (GUÉRIOS, AGRANIONIH E ZIMER, 2014, p. 15)

\section{REFERÊNCIAS}

ALBUQUeRQUE, R. K. de; LEAL, T. Feraz; PESSOA, A. C. R. G. O tempo Escolar em Propostas Interdisciplinares de Ensino: a leitura como elo integrado do ensino. Pacto Nacional pela Alfabetização na Idade Certa. Caderno de Apresentação / Ministério da Educação, Secretaria de Educação Básica, Diretoria de Apoio à Gestão Educacional. - Brasília: MEC, SEB, 2015.

BRASIL. Define Diretrizes Curriculares Nacionais Gerais para o Ensino Fundamental. Resolução CNE/CEB 7/2010. Diário Oficial da União, Brasília, 15 de dezembro de 2010a, Seção 1, p. 34.

BRASIL. Resolução CNE/CP n 4/2010. Define Diretrizes Curriculares Nacionais Gerais para a Educação Básica. Diário Oficial da União, [da República Federativa do Brasill, Brasília. DF, 14 jul. 2010b. Seção I, p. 824.

BRASIL. Secretaria de Educação Básica. Diretoria de Apoio à Gestão Educacional. Pacto Nacional pela Alfabetização na Idade Certa: Caderno de Apresentação / Ministério da Educação, Secretaria de Educação Básica, Diretoria de Apoio à Gestão Educacional. - Brasília: MEC, SEB, 2014.

CANÁRIO, R. A Escola tem Futuro? Das Promessas às Incertezas. Porto Alegre: Artmed, 2006.

CELLARD, A. A Análise Documental. In: POUPART, J. et al. A Pesquisa Qualitativa: Enfoques Epistemológicos e Metodológicos. Petrópolis: Vozes, 2008

CRESWELL, J. Projeto de Pesquisa: Métodos Qualitativo, Quantitativo e Misto. Porto Alegre: Artmed, 2007.

FERREIRA, A. T. B.; LEAL, T. F. A formação continuada de professores: enfim o que pensam e sugerem os docentes? In Formação continuada de professores: Reflexões sobre a prática. Recife: Editora Universitária, UFPE, 2010.

FERREIRA, A. T. B.; LEAL, T. F. Formação de professores: princípios e estratégias formativas. Pacto nacional pela alfabetização na idade certa: formação de professores no pacto nacional pela alfabetização na idade 
certa / Ministério da Educação, Secretaria de Educação Básica, Diretoria de Apoio à Gestão Educacional. -- Brasília: MEC, SEB, 2012.

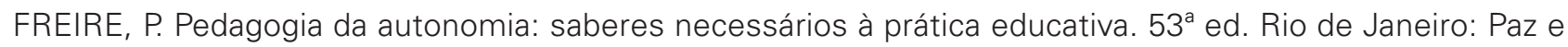
Terra, 2016

GUERIOS, E. C.; AGRANIONIH, N. T.; ZIMER, T.T. Situações Aditivas e Multiplicativas no Ciclo de Alfabetização. Pacto Nacional pela Alfabetização na Idade Certa: Operações na resolução de problemas/ Ministério da Educação, Secretaria de Educação Básica, Diretoria de Apoio à Gestão Educacional. - Brasília: MEC, SEB, 2014.

GUERIOS, E.; LIGESKI, A. Resolução de problemas em matemática: problemas em matemática ou linguagem? In: Congresso Iberoamericano de Educação Matemática,6.2013 Disponível em: <www.cibem.org/paginad/ img/resimenes.pdf>. Acessado em: junho de 2014.

IMBERNÓN, F. Formação continuada de professores, Porto Alegre: Artmed, 2010.

LAUTER, S. L.; SPINILLO, A. G. As relações entre o desempenho em problemas de divisão e as concepções de crianças sobre divisão. Psicologia: Teoria e Pesquisa, set-dez, 2002, vol. 18, n.3, p.237-246.

LIBÂNEO, J. C. Didática, 2ed. São Paulo: Cortez, 2013.

LOPES, A. J. Os saberes das crianças como ponto de partida para o trabalho pedagógico. Pacto Nacional pela Alfabetização na Idade Certa: Caderno de Apresentação / Ministério da Educação, Secretaria de Educação Básica, Diretoria de Apoio à Gestão Educacional. - Brasília: MEC, SEB, 2014.

MENDES, A. B.; GOMES, R.; SILVA, J. S. da. A interdisciplinaridade no Ciclo de Alfabetização. Pacto Nacional pela Alfabetização na Idade Certa. Caderno de Apresentação / Ministério da Educação, Secretaria de Educação Básica, Diretoria de Apoio à Gestão Educacional. - Brasília: MEC, SEB, 2015. 76.

MINAYO, M. C. de S. O Desafio do Conhecimento: Pesquisa Qualitativa em Saúde. 10 ed. São Paulo: Editora Hucitec, 2007.

MORAES, R.; GALIAZZI, M. do C. Análise Textual Discursiva. ljuí: UNIJUÍ, 2007.

MUNIZ, C. A. Brincar e jogar: enlaces teóricos e metodológicos no campo da educação matemática. Belo Horizonte: Autêntica, 2010.

NACARATO, A. M.; MENGALI, B. L. da S.; PASSOS, C. L. B. A Matemática nos Anos Iniciais do Ensino Fundamental: Tecendo Fios do Ensinar e do Aprender. Belo Horizonte: Autêntica Editora, 2009.

NUNES, T.; BRYANT, P. Crianças Fazendo Matemática. Porto Alegre: Artmed, 1997.

NUNES, T. et al. Educação Matemática: números e operações numéricas. São Paulo: Cortez Editora, 2009.

PARK, J.-H.; NUNES, T. The developmentoftheconceptofmultiplication. Volume 16, vol. 3, Jul-Set, 2001, p. 763-773.

SOUZA, E. K. de. Formação Continuada de Professores na Área da Matemática Inicial. Tese (Doutorado) Universidade Federal do Rio Grande do Sul, Faculdade de Educação, Programa de Pós-Graduação em Educação, Porto Alegre, BR-RS, 173 f, 2014. 
TARDIF, M. Saberes Profissionais dos Professores e Conhecimentos Universitários: Elementos para uma Epistemologia da Prática Profissional dos Professores e suas Consequências em Relação à Formação para o Magistério. Revista Brasileira de Educação, no. 13, jan/abr, 2000.

TARDIF, M. Saberes Docentes e Formação Profissional. 2. ed. Petrópolis: Vozes, 2002, 325p.

VERGNAUD, G. Multiplicativestructures. In Lesh, R. and Landau, M. (Eds.) AcquisitionofMathematicsConceptsand Processes. New York: Academic Press Inc., 1983, p. 127-174.

VERGNAUD, G. Teoria dos campos conceituais. In Nasser, L. (Ed.) Anais do $1^{\circ}$ Seminário Internacional de Educação Matemática do Rio de Janeiro, 1993, p. 1-26.

SOUZA, E. K.; DORNELES, B. V.; FRANCO, S. R. K.; Formação continuada de professores: reflexões sobre o desenvolvimento do raciocínio multiplicativo no ciclo de alfabetização Formação Docente - Revista Brasileira de Pesquisa sobre Formação de Professores. Belo Horizonte. Vol. 13, nº 25 (p. 261-278) 31 dez. 2020. ISSN:2176-4360. DOI https:// doi.org/10.31639/rbpfp.v13i25.407 